\title{
Application of Comprehensive Landing Method During the Rectification for the Brick-concrete Buildings in Soft Soil Area
}

\author{
Zhang Xiao-nan ${ }^{1, *}$, Shi San-yuan ${ }^{1}$, Wang Xiao-lei ${ }^{1}$ and Zhao Hong-yu ${ }^{2}$ \\ ${ }^{1}$ School of Civil Engineering, Hebei University of Engineering, Handan, 056038, P.R. China \\ ${ }^{2}$ School of Arts, Hebei University of Engineering, Handan, 056038, P.R. China
}

\begin{abstract}
This paper first analyzes the tilting reasons of a brick-concrete building in Yunnan province in China. Then, a comprehensive rectification method which combines the stress release method and the excavation of stress release trench was put forward. This method uses the anchor static pile in order to guarantee the safety of the building in the process of rectifying. The practice case showed that the inclination rate of the building returned to $3 \%$ from $14.4 \%$, which proved the efficiency of the proposed method.
\end{abstract}

Keywords: Soft-soil, Brick-concrete structure, Rectification, Reinforcement, Forced landing settlement.

\section{INTRODUCTION}

There are different reasons of buildings to tilt due to the soil properties of the buildings in different areas which always have the great characteristics of the regional differences. First, the movement of water often causes the uneven settlement of building foundation in collapsible loess area [1]. Second, the foundation problem often produces differential settlement in soft-clay area [2]. At the same time, due to the improper investigation, design or construction and other human factors, often result in a greater differential settlement. Different structures of the buildings show different resistance to the uneven settlement. If beyond the bearing capacity, the internal structural will be destroyed, and the buildings cannot function normally [3-5].

Terracina, 1962, presented a homemade underground pumping for the issue about the tilt of the Leaning Tower of Pisa in 1962 [6]. And the Bertrand Kahn Canadian Barn, which was built in 1941, used the jacking technology of rectification [7]. And in our country, Professor Liu Zu-de, 1989, proposed a method of rectification to dig the deep soil in a virtual way-the stress relieving method [8]. Professor TANG Ye-qing invented the setting caisson, a special method for rectification which emits high-pressure water from the radial collector well through the hole wall [9].

Different methods of rectification are used on different buildings for different tilting reasons during the progress of disciplines. Cut-pile forced settlement landing is a new method for the building rectification. Unlike the previous correction methods, it is designed to use certain technology to cut off the vertical component on the smaller subsidence of structures, so as to force the structure to decrease. Now there are a few reports about this rectification method in practical

*Address correspondence to this author at the School of Civil Engineering, Hebei University of Engineering, Handan, 056038, P.R. China;

E-mail: zxn863726147@163.com engineering applications. Xu Bang-long, 2001 [10], who started a project with the methods of rectification and reinforcement, for instance, in a residential building of Zhou Shan City, showed us two kinds of methods. One is anchored pile foundation underpinning and the other is cut-pile forced settlement landing combined with digging the deep soil. Both of these methods were used to deal with the uneven settlement of cement mixing pile's composite foundation of the buildings in a comprehensive way. Li Xiang-yang, 2002 [11] , gave us another example of the rectification method in a five-story building of San Men Xia City. He showed us the process of design and construction which used the technology of jacking to rectify. And Chen Li-rong, 2004 [12, 13], continued the study of the process and the effect on the reinforcement construction, with the case of one pile foundation's rectifying of a certain building.

The tilt of buildings would not only bring a lot of inconvenience in our life, but also cause serious building collapse, heavy casualties, and seriously social impacts. However, the construction rectification started late in our country. And now, the rectification and reinforcement mainly depends on the sophisticated construction methods and designed techniques, but it has not formed a systematic theory or technique to reference.

This paper puts forward a systematic research on tilt building, including the reasons, the rectification and the reinforcement methods, which combined with an example of brick-concrete building in soft-clay area of Yunnan Province. Therefore, it has a great value for similar rectification projects.

\section{PROJECT OVERVIEW}

\subsection{Project Introduction}

The building in the project is a six-layer (seven-layer partially) brick-concrete structure without any basements in 
Yunnan Province, with the length of $106 \mathrm{~m}$ from west to east, and with the width of $12 \mathrm{~m}$ from north to south. In addition, the height of the building is $20.7 \mathrm{~m}$. The foundation under wall with a single row of pile, is a soil cement pile with the Size A (s) stirring core, the diameter of which is $500 \mathrm{~mm}$ and the length of which is $11.1 \mathrm{~m}-17.6 \mathrm{~m}$. The core pile is the precast concrete square pile, with section size of $250 \mathrm{~mm} \times 250 \mathrm{~mm}$, concrete strength of C30, and the length of which is $9.0 \mathrm{~m}$.

The observations of the project began when the two-story of the main structure was completed in December 2010, and then, the observations continued once when every two story were completed. When the main structure was totally completed in December 2011, the north side of the building obviously tilted. The maximum ramp rate was $16.9 \%$, and the average ramp rate was $14.4 \%$, which was much higher than the allowable rate of $4 \%$. The surrounding facade and layout of buildings are in Fig. (1), and Fig. (2).

\subsection{The Soil Properties in the Site}

According to the survey, the site was originally farmland and shallow pond, and was filled with soil later. Moreover, according to the geological survey report, from top to bottom

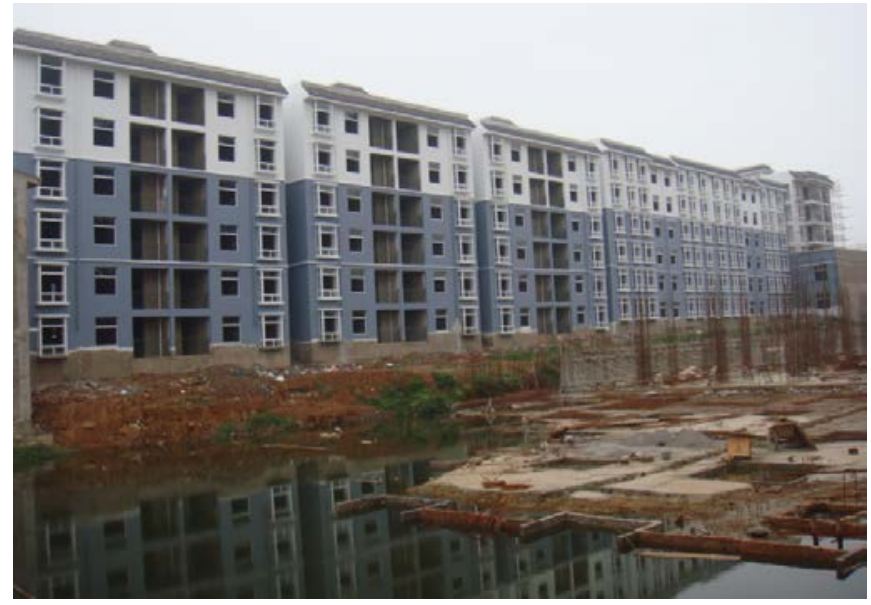

Fig. (1). Architecture elevation drawing.

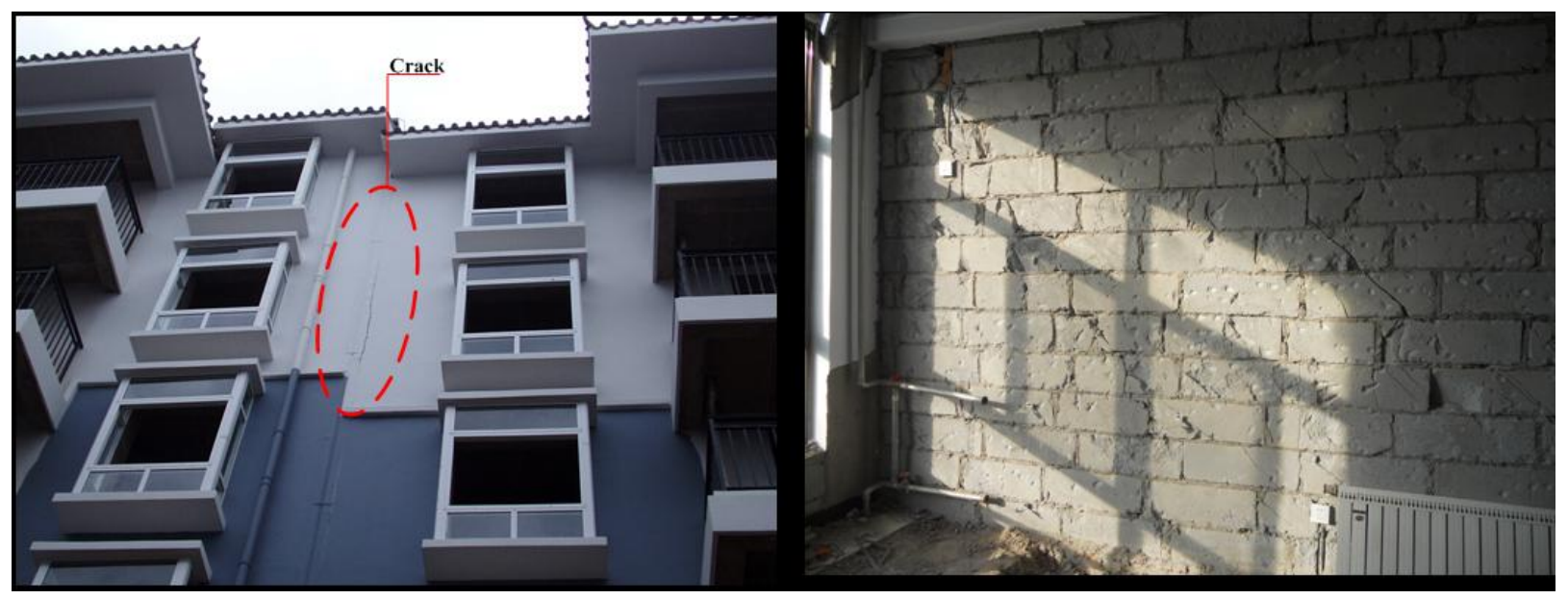

Fig. (2). Architecture layout around.

Table 1. Numerical results for slope stability.

\begin{tabular}{|c|c|c|c|c|c|c|c|}
\hline $\begin{array}{l}\text { Soil Strata } \\
\text { Number }\end{array}$ & $\begin{array}{l}\text { Soil Strata } \\
\text { Name }\end{array}$ & $\begin{array}{c}\text { Natural Water } \\
\text { Content \% }\end{array}$ & $\begin{array}{c}\text { Natural Void } \\
\text { Ratio } e_{0}\end{array}$ & $\begin{array}{l}\text { Natural Density } \\
\quad \rho\left(g / \mathbf{c m}^{3}\right)\end{array}$ & $\begin{array}{c}\text { Internal Friction } \\
\text { Angle } \varphi(0)\end{array}$ & $\begin{array}{l}\text { Cohesion } \\
\text { C(KPa) }\end{array}$ & $\begin{array}{c}\text { The Average Thickness } \\
\text { Of the Soil (m) }\end{array}$ \\
\hline (1) & Plain Fill & 33.55 & 0.91 & 1.77 & 10.26 & 5.07 & 4.5 \\
\hline (2) & Mucky Soil & 70.36 & 1.868 & 1.59 & 3.89 & 10.07 & 3 \\
\hline (3) & Organic Clay & 61.93 & 1.66 & 1.64 & 5.83 & 12.02 & 3 \\
\hline (4) & Silty Clay & 36.00 & 0.99 & 1.85 & 7.75 & 14.20 & 1 \\
\hline (5) & Silt & 38.12 & 1.05 & 1.83 & 11.51 & 12.35 & 3 \\
\hline (6) & Circular-gravel & 16.03 & 0.45 & 2.1 & - & 0 & - \\
\hline
\end{tabular}


the main kinds of the soil was plain fill, mucky soil, organic clay, silty clay, silt and circular-gravel (a typical geological section is shown in Fig. 3). The miscellaneous fill strata and the soft soil were thick. The underground water was $1.0 \mathrm{~m} \sim$ $2.5 \mathrm{~m}$ from the earth, and the components of the soil and the main physical indicators are listed in Table $\mathbf{1}$

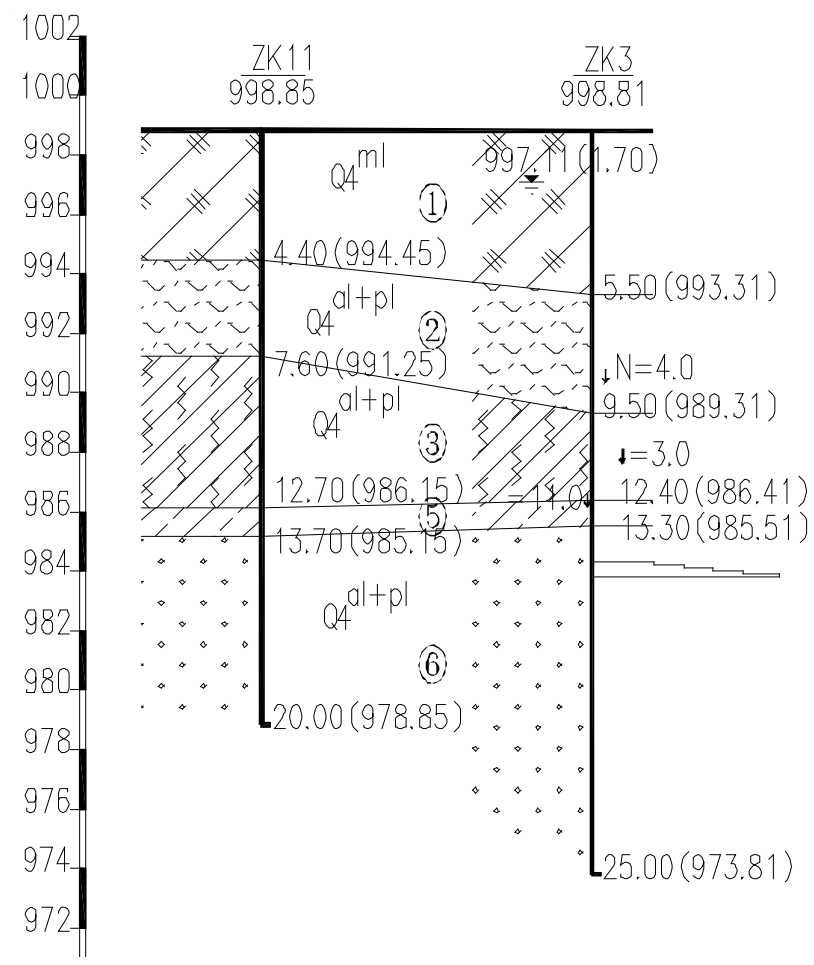

Fig. (3). Typical geological section.

\section{CAUSE ANALYSIS OF BUILDING TILTING}

There are many kinds of reasons for the uneven settlement and differential settlement of the buildings in soft soil foundation. Through the actual research and geological prospecting situation, we found that the main reason for the uneven settlement of our case is in three areas, loads from the superstructure, foundation and infrastructure programs, as well as the surrounding environment.

\subsection{Differences of Structural Load}

There is the significant height different between the six-layer construction and the seven-layer construction. Meanwhile, the north side of the building is the room of small square with lots of vertical and horizontal walls, and the weight load is big comparatively. However, the south side of the building is spacious living room, bedroom and other rooms layout. Therefore, the center of gravity is different from centroid, which leads to the uneven settlement to the north.

\subsection{Foundation}

The plain soil which was filled in the original farmland and pond, was $4 \mathrm{~m}-5 \mathrm{~m}$ thick and was in the state of consolidations. Therefore, the construction load on the ground leads to unsettlement underground.
In this case, the ratio between the length of the core and that of the pile is 0.81 , which did not satisfy the required the rate of 0.87 in "Core and Pile Technical Specification" in Yunnan Province.

In order to verify the actual carrying capacity of the stirring cored pile, under the foundation beams six piles are selected to have the static load test. The deformation curve is shown in Fig. (4). Obviously, the pile 3 \# having the ultimate bearing capacity greater than the designed $900 \mathrm{kN}$, the capacity of the pie 5 \# and the 6 \# pile reached $520 \mathrm{kN}$, which is much smaller than the design value. So the bearing capacity of single pile did not meet the designed requirements, which was also one of the main reasons leading to the occurrence of uneven settlement building.

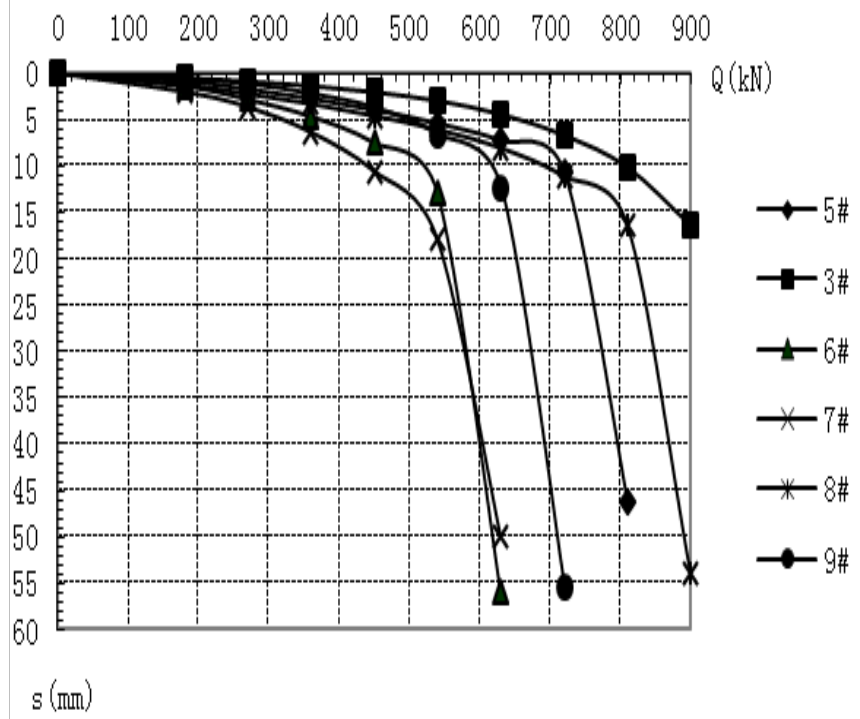

Fig. (4). Q-s curve.

\subsection{Surroundings}

There was a new building project to the north side of this case (the relative position is shown in Fig. 5). Because the groundwater level of the new building site was shallow, pitting dewatering was implemented.

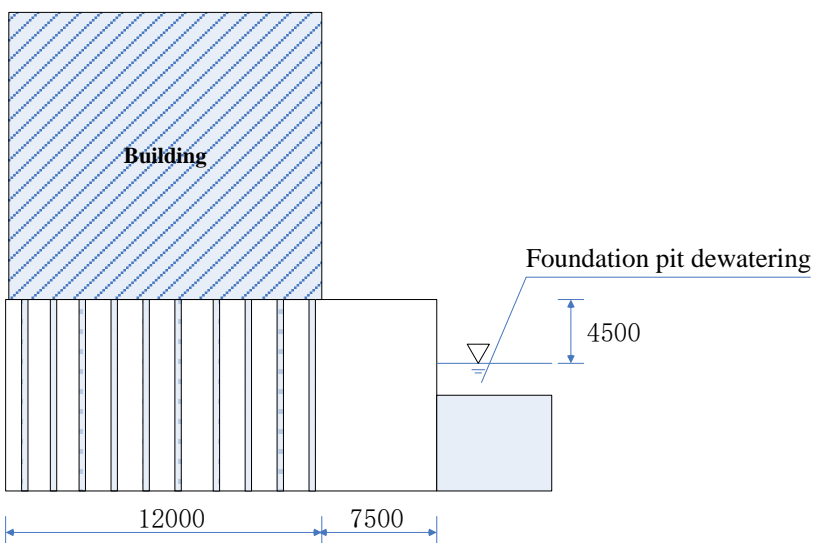

Fig. (5). The relative position.

The foundation pit of the new building was quite near to the one in our case, so the pumping of the former led to the 
lower water level of the letter one, which further leads to a greater consolidation settlement. Moreover, there were no support measures around the foundation pit of the north new building, giving the south building the stress relief effect. In other words, the building tended to tilt to the north.

\section{REINFORCEMENT MEASURE}

\subsection{Reinforcement Scheme}

Through the analysis above, the main reasons of the building tilt include the core of structure moving to the north, the lacking of the bearing capacity of the pile foundation, the excavation and pumping on the adjacent buildings. And after the continuous observations on settlement it is revealed that the house has not yet reached a stable settlement, the settlement and differential settlement are continuing, and the subsidence rate has an increasing trend. Therefore, the status of the tilt building, call for urgent measures for rectification and reinforcement. The main measures are as follows:

(1) In order to solve the growing problems of continuous pumping in the north building site which caused differential settlement of the building in our case, a row of jet grouting piles with the diameter of $600 \mathrm{~mm}$ are ereced about $3.0 \mathrm{~m}$ away from the case building, with the piles $2 \mathrm{~m}$ 's deep into the breccia layer, forming the waterproof curtain to weaken the influence of pumping in the pit of the north building. At the same time, the row also plays a role for strengthening the pit to prevent the soil layer from moving toward the north side horizontally.

(2) Since the building is a brick and concrete structure, secondary damage may occur in the process of rectification. So we have the raft foundation construction on the north side of the building to enhance structural integrity.

\subsection{Rectification Scheme}

The rectification of the existing buildings should be carried out in harmously, smoothly and slowly. Because the structure is surrounded by a large number of buildings (Fig. 2), and the water level under it is shallow, if taking the methods of precipitation, the uneven consolidation settlement might also have occurred to the surrounding buildings. Moreover, due to the space constraints, the method of digging soil is not effective. Based on the above considerations, the project uses a comprehensive rectification, combining stress release method and cut-pile forced landing settlement.

(1) The excavation of stress release trench to eliminate the horizontal stress of soil foundation

The shallow soil of the foundation is new backfill one, so a stress release trench, is excavated, $1.0 \mathrm{~m}$ wide and $3.0 \mathrm{~m}$ deep on the south side of the building, notched or drilled vertical wells on the south side of the structure of the foundation, in order to relieve the horizontal stress of the foundation soil on this side, and led to produce the vertical deformation of the soil.

(2) The method of cutting piles in the south side of the building to enforce ground settlement in the south

According to the load of the upper structure, piles which can better reflect the force on the structure are chosen, to conduct the pile static load test, so as to determine the pile capacity and the $\mathrm{Q} \sim \mathrm{s}$ deformation curve.

After obtaining the static pile load test results, according to the loading characteristics of the structure, the piles under the longitudinal wall and the transverse wall of south side are chose to be truncated. The number of the truncated piles is determined by the results of the pile static load test. The remaining pile force should meet the load values on the $\mathrm{Q} \sim \mathrm{s}$ curve, or reach 0.7 time of the ultimate bearing capacity of the pile foundation, to make sure that the force of each pile would not exceed its limited load after the pie cutting.

$\mathrm{n}$ view that the settlement of the east side is smaller than that of the west side, the order of the pile cutting is from the east side to the west side in a gradual transition, and determined the new schedule and batch of the pile truncating are determined according to the settlement observations. The batches of the pile cutting make it possible to make the south of the building a gradually sinking due to its own weight, until the tilting rate of the building meets the regulatory requirements. The truncation order of the pile foundation is shown in Fig. (6), and the site of pile cutting is shown in Fig. (7).

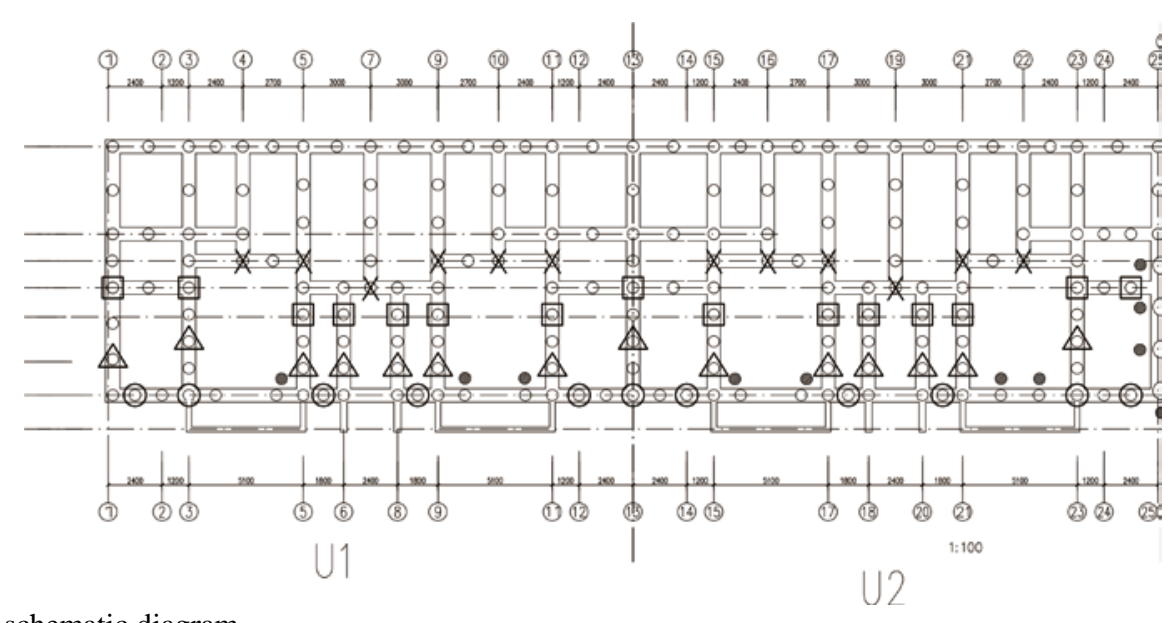

Fig. (6). Chopping pile schematic diagram.

(The batch $(O, \Delta, \square)$ shows the order of pie cutting, the others were the same with unit1 and unit2) 


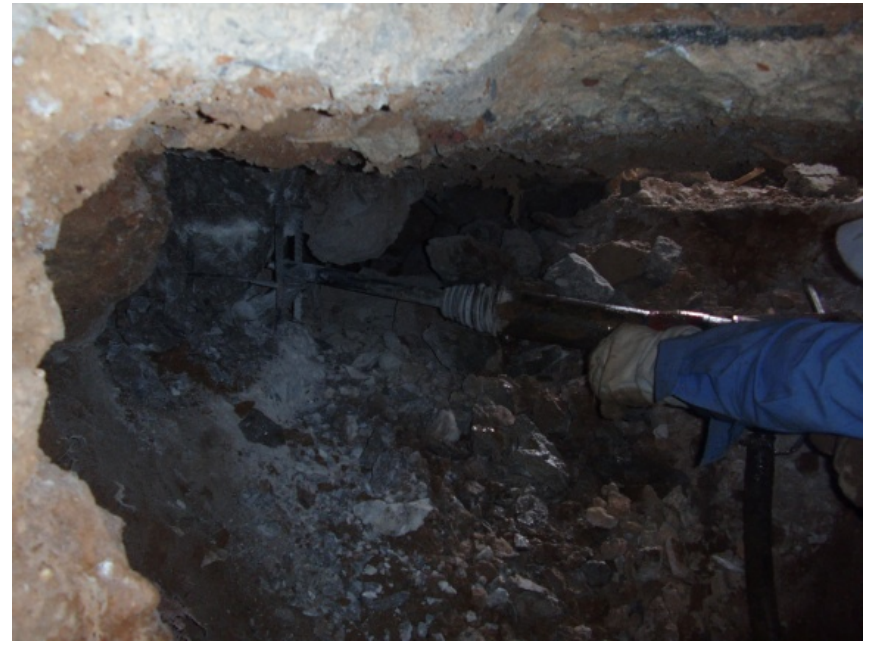

Fig. (7). The scene of cutting pile.

\subsection{The Tilting Measure}

In order to prevent the building from tilting back again after rectification, the anchor piles are added on both sides of the foundation beams of the building (shown in Fig. 8), and the number of the anchor pile is determined after the accounted foundation bearing capacity. The trapezoidal pile hole is reserved and size is big on top and small on bottom, so as to make the pile form an effective embedded solid force when the pouring of concrete is totally healed. The process of pressing piles is bidirectionally controlled by the depth and pressure piling force, with the guiding pile holes if necessary.

\subsection{The Observation of Settlement in the Process of Rectification}

In order to control the degree of tilting back during the rectification, the settlement of the building must be observed. A monitoring system is set up on the site in the program of the rectification, with two methods of the measurement in the field, the leveling measuring method and the dial indicator observation. These two methods became complementary to each other to ensure the accuracy of the observation.
(1) The leveling measuring method

The electronic level measurement is used in the settlement observation, 2 level basis points are laid on the foundation without external disturbances, which is beyond the range of the foundation deformation. Meanwhile, the elevation of the basic points are corrected regularly, which will ensure the standard of the point elevation values would not have any changes.

The settlement observation point of the building is made up of angle steel. In order to reflect truly and objectively the state of the stress and the deformation of tilting back, the settlement observation point is set in the main parts of the building. Moreover, the points are covered to prevent the external disturbance. The settlement observation points of the rectification are evenly arranged according to the surface distributing load, and 13 points are set on the north side the building and the others are on the south, so as to make a total of 28 settlement observation points. The necessary measures are taken to ensure the buildings safe after the rectification in accordance with the settlement monitoring data in time.

\section{(2) The dial indicator observation}

During the rectification and the reinforcement of the building, the dial indicator observation is often used for the correction value of the building, which can get the correction value of a point relatively straightforward. However errors may occur due to the soil settlement in this dial indicator observation, so this observation is combined with the leveling measuring method to get the value accurately.

The dial is selected at the featured parts of the building, and fixed on the hard base. Moreover, the contacting parts of the building and the ends of the dial are flatted, so as to prevent the external shocks from the data of dial. During the process of the rectification, the larger relatively stiff areas are chosen to set the dials, the monitoring points are observed frequently, the monitoring data are caculated, and the situation of tilting back is reported in time. The dials are shown in Fig. (9).

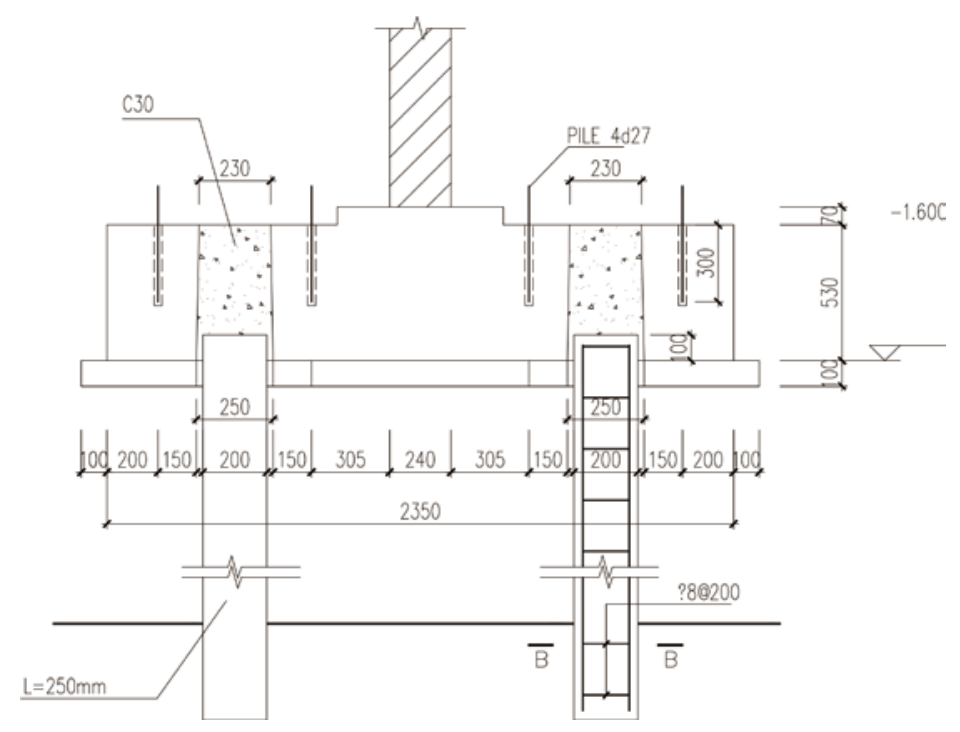

Fig. (8). Anchor jacked pile system. 


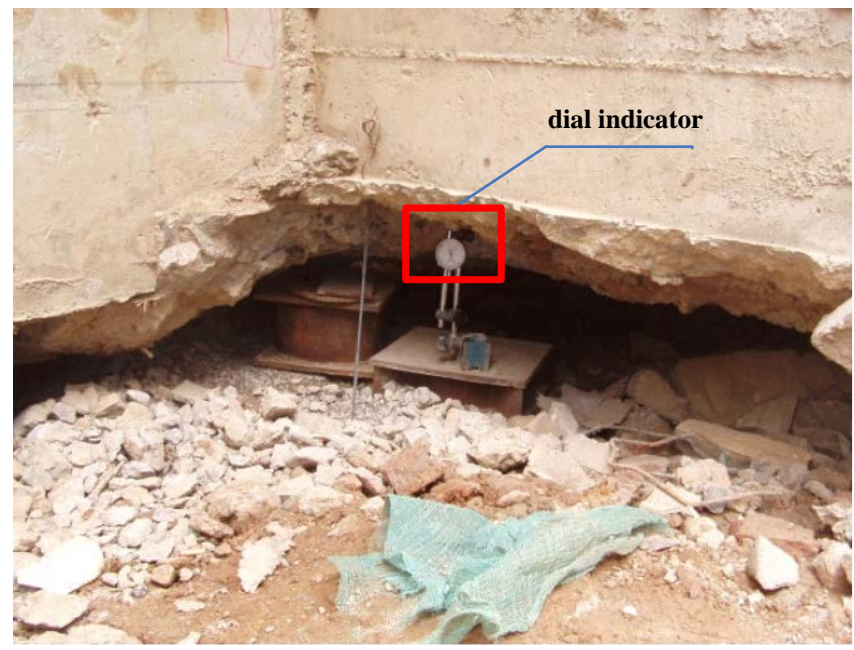

Fig. (9). The dial indicator in position.

\subsection{The evaluation of the rectification}

The observations of settlement were conducted from the pie cutting to the pile sealing during the rectification of the building. Each monitoring points and the curves of the settlement were shown in Fig. (10) and Fig. (11).

The two pictures are conducted by the soft Origin 8.0, and the observation points of settlement are entered one by one, although the project is huge, but the pictures are more persuasiveness for the researchers [14].

Meanwhile, It could be seen from the curve of the settlement observation that after the completion of pile cutting on the stage of $\mathrm{G}$, the settlement was gradually stabilized. Moreover, it is indicated that the settlement stopped if the results of the monitoring settlement are basically unchanged till the next week.

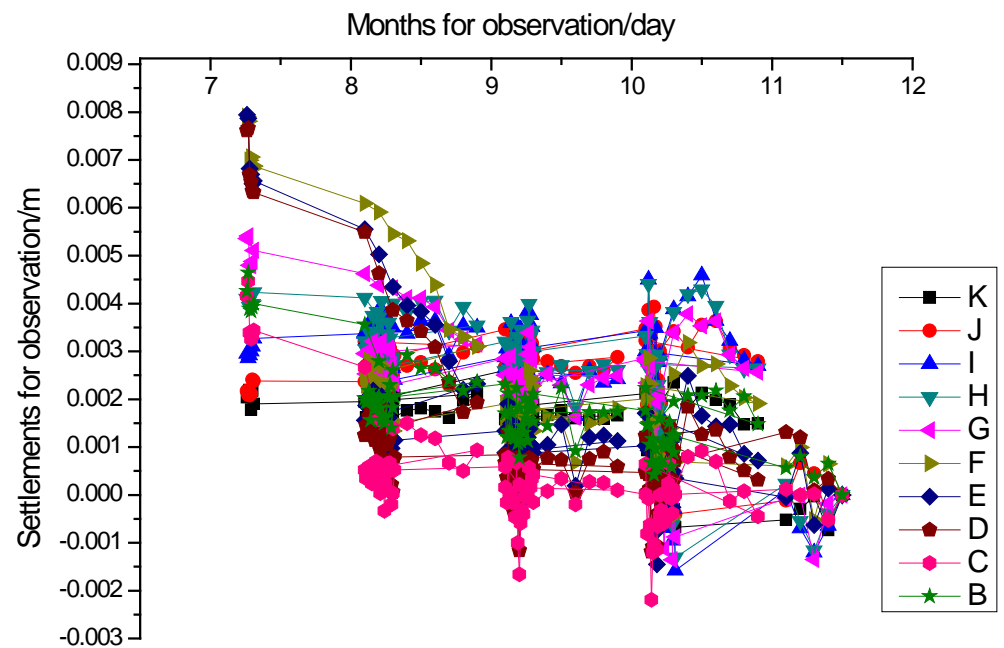

Fig. (10). The curve of the settlement observation on the north side.

(K-the north construction of the anchor static pile; B - the south construction of the anchor static pile; C,E-the order of pie cutting; D,F-upper load in the south grouting; G,J—-the finish of pie cutting ; H,I—the pile sealing)

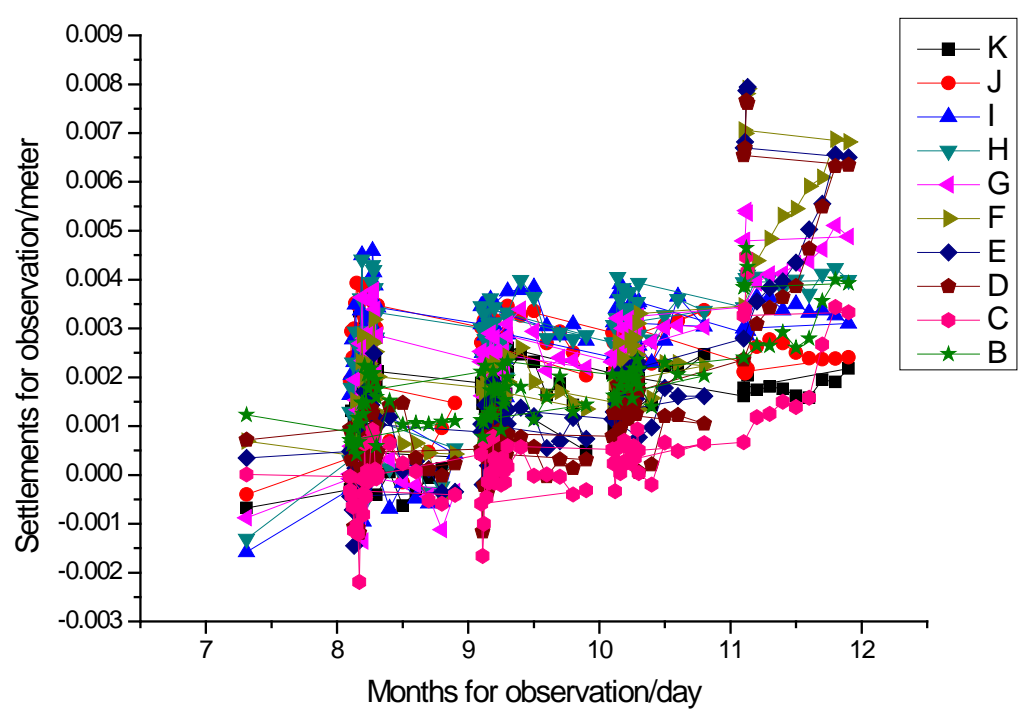

Fig. (11). The curve of the settlement observation on the south side.

(K-the north construction of the anchor static pile; B-the south construction of the anchor static pile; C,E-the order of pie cutting; $\mathrm{D}, \mathrm{F}$ - upper load in the south grouting; G,J—-the finish of pie cutting; H,I—the pile sealing) 
The rectification of the building had lasted 43 days since November 3, 2011, with the 459 piles of the project, and 291 cutting piles. The maximum inclination rate was reduced to less than $3 \%$ in the end, and the architectural distortion was stabilized.

\section{CONCLUSION}

Through the successful implementation of the rectification and the reinforcement of the brick-concrete building, the following understandings in engineering design and construction are achieved.

(1) The factors (excavation, precipitation) of the surrounding environment and the basic design problems of architecture are the major causes of the uneven settlement of buildings.

(2) It is feasible to use a comprehensive rectification method, to combine the stress release method combined with pile cutting forced landing settlement method, featured by short time constructions and quickness of tilting back.

(3) It is not possible to control precisely the process of tilting back, because many factors affect the rectification of the building. Therefore, only by information-oriented construction method can we take measures to control the settlement timely. It is not only the detection method of the effect for the rectification, but a more effective means of controlling settlement.

Based on the analysis of the tilt reasons of the brick-concrete building, it can be drawn that the effects of the excavation and precipitation to the surrounding environment should be considered during the construction process. Meanwhile, the case in this study provides beneficial references for similar projects in the future.

\section{CONFLICT OF INTEREST}

The authors confirm that this article content has no conflict of interest.

\section{ACKNOWLEDGEMENTS}

The work was accomplished within the Nation Science Foundation Project (51174124).

\section{REFERENCES}

[1] S. Yu, Z. Gui-wen, and L. Chun-yan, "The research and practice on the loess foundation for the scheme rectification in masonry building”, Building Structures, vol. 32, pp. 13-15, 2012.

[2] L. Tao, and G. Da-zhao, "The rectification for a residential building with the method precipitation in Shanghai”, Engineering Survey, vol. 1, pp. 39-42, 2014.

[3] GB 50007-2012. Building Foundation Design Code. Beijing: China Building Industry Press, 2012. (in Chinese).

[4] GB 50007-2012. Code for Design of Building Foundation. Beijing: China architecture \& Building Press, 2012. (in Chinese).

[5] S. Zhuang-li, and W. Zhen, "Thinking for some key technology of pagodas incline-rectifying”. Special Engineering Technologies, vol. 72, no. 3, pp. 120-124 2013, (in Chinese).

[6] N. M. Punnivakottv, J. Y. Liew, and N. E. S. Rihcard, "Nonlinear analysis framework by cable-ensioning of Self erecting technique”, Journal of Structural Engineering, vol. 136, no. 3, pp. 361-370, 2000.

[7] S. M. T. Ranzani, "Stabilisation of leaning structures: The tower of Pisa case”, Geotechnique, vol. 51, no. 7, pp. 647-648, 2012.

[8] K. Sior, K. Jong-min, and C. Myn-Chae, "A new proportioning method for member sections of single layer reticulated domes subjected to uniform and non-uniform loads", Engineering Structure, vol. 25, no. 10, pp. 1265-1278, 2013.

[9] N. Zu-de, "Stress relieving for the process of rectification", Geotechnical Foundation, vol. 4, pp. 1-6, 2010.

[10] N. Guohua, and L. Ren-huai, "Nonlinear elastic theory of rectangular reticulated Shallow shells structures”, Applied Mathematics and Mechanics, vol. 15, no. 5, pp. 413-423, 2013.

[11] L. Xiang-yang, and T. Zhi, "The rectification with pile cutting for buildings”, Engineering Survey, vol. 6, pp. 45-47, 2013.

[12] K. J. Bathe, and M.R. Khoshvoftar, "Finite Element Formulation and of Nonlinear Heat Transfer”, Nuclear Engineering and Design, vol. 51, pp. 389-401, 2011.

[13] M. Salador, M. J. Francisco, and F. Pedro, "Nonlinear axisymmetrical Behavior and stability of singl-layer reticulated domes”, Central Scientific Research of Building Structure, vol. 1 , pp. 504-523, 2014.

[14] J. Burland, "The stabilization of the learning tower of pisa”, Journal of Architectural Conservation, vol. 8, no. 3, pp. 7-23, 2012.

Received: September 17, 2014

Revised: December 17, 2014

Accepted: December 23, 2014

(c) Xiao-nan et al.; Licensee Bentham Open.

This is an open access article licensed under the terms of the Creative Commons Attribution Non-Commercial License (http://creativecommons.org/licenses/ by-nc/3.0/) which permits unrestricted, non-commercial use, distribution and reproduction in any medium, provided the work is properly cited. 